\title{
Is rate of return pricing a useful approach when value-based pricing is not appropriate?
}

\author{
Michael Drummond ${ }^{1} \cdot$ Adrian Towse $^{2}$
}

Published online: 15 February 2019

๑) Springer-Verlag GmbH Germany, part of Springer Nature 2019

\section{Introduction}

The pricing of new health technologies, such as drugs or devices, involves deciding how the economic surplus generated by the new technology is shared between the producer and consumer. In theory this division is determined by the market-clearing price. However, in health care markets, third party payers act for patients, and suppliers of technologies have patent protection, so the price of a new technology has to be agreed by these two parties.

There are several rules for the pricing of new health technologies, in particular drugs, but the majority of health economists consider value-based pricing to be the method of choice [2]. This approach is now well-established in those countries, such as the United Kingdom, that use health technology assessment, incorporating economic evaluation, as a basis for recommending the reimbursement or use of new technologies. Under this approach, the price of the new technology is determined by the maximum price that would result in the incremental cost- effectiveness ratio (ICER) of the new technology (compared to current care) being no more than the decision-making 'threshold' of the third party payer in the jurisdiction concerned. Value-based pricing (VBP) is considered by many to be far superior to most of the alternatives, such as uninformed price negotiations, or internal or external reference pricing [6].

However, there are issues in the application of VBP, with differences of opinion about what constitutes 'value' and about the determination of the 'cost-effectiveness threshold' against which value is to be judged [4]. For example, should it be determined based on the current marginal productivity of the health care system, so as to avoid any loss in health

Michael Drummond

mike.drummond@york.ac.uk

1 Centre for Health Economics, Alcuin 'A' Block, University of York, Heslington, York YO10 5DD, UK

2 Office of Health Economics, London, UK when new technologies are introduced, or should it reflect the preferences of citizens for additional spending on health and health related gain, so that optimal levels of industry R\&D will incentivized [5]. Some have criticized the concept of VBP, arguing that it may enable innovators to extract too much value from their innovations, at the expense of value to the public [7]. Therefore, this paper discusses whether an alternative approach, rate of return pricing, could be useful in situations where, for whatever reason, VBP is considered to be inappropriate.

\section{When might value-based pricing be considered to be inappropriate?}

The first case where value-based pricing might be deemed to be inappropriate is in the pricing of treatments for ultra-rare diseases. Here, treatments such as enzyme-replacement, can cost as much as $\$ 500,000$ per year. So even if they extended life at full health, it is unlikely that they could ever be considered to be cost-effective when judged against conventional standards. In addition, these therapies often fulfill a previously unmet need and therefore there is no existing therapy to be replaced, which might generate cost-offsets. Therefore, if, for whatever reason, it is decided to reimburse these therapies, VBP is unlikely to be helpful in setting an appropriate price, since the price will be too low, either to encourage manufacturers to launch the products, or, in the long run, to stimulate research into rare conditions.

However, by departing from the VBP, Côté and Keating argue that policy makers are at risk being exploited by manufacturers and patient groups, since their 'willingness to pay is high, because of the seriousness of the disease, the absence of treatment alternatives, and the possibility of identifying the individuals and families affected by the decision' [3]. They point out that orphan drugs have become a 'highly lucrative opportunity for manufacturers', since 'in 2008 , of 18 products intended solely for the treatment of a 
rare disease 11 had achieved global annual sales equal to or greater than $\$ 1$ billion during the 7-year exclusivity period granted by the FDA'.

A second case where the VBP may be deemed inappropriate is in the pricing of 'cures', such as gene therapy, for conditions that are currently being treated at great expense. For example, suppose that a gene therapy became available for those patients on long-term haemodialysis. If the need for life-long dialysis could be obviated, such a cure could be worth millions of dollars based on cost savings from current care alone. If the new therapy was considered to offer a higher quality of care, the price implied by an ICER up to the jurisdiction's current decision-making threshold would likely be even higher. Therefore, such a treatment could command an exceptionally high price if VBP were applied.

Of course, considering VBP to be 'inappropriate' (either 'too high' or 'too low') in these situations is itself a value judgment. It might be argued that, in the case of rare diseases, therapy should not be made available unless manufacturers were willing to drop their prices dramatically [8], or alternatively, in the case of 'cures,' that exceptionally high rewards should be given to manufacturers who discover a replacement for highly expensive therapies, or therapies which transform life expectancy or quality of life. However, we argue that many health care payers would have difficulties with both of these propositions.

Of course, payers can negotiate with the manufacturer in these situations. For example, in the case of a cure for a disease currently being treated with an expensive therapy, they could argue that current therapy itself is not cost-effective and therefore not the appropriate comparator for new treatment, or that any savings from replacing the current, expensive, therapy should be shared between the manufacturer and the payer. However, in such a negotiation, policy makers need guidance on what might constitute a reasonable price, if the VBP is not deemed to be appropriate.

\section{Rate of return pricing}

As the name implies, rate of return pricing is based on ensuring a pre-specified rate of return to manufacturers, after covering the costs of developing and marketing the product. It has been used in the pricing of the products of public utilities, and in the defence industry outside of the procurement of finished products. The latter case is closest to the pharmaceutical industry, as, like pharmaceuticals, new defence products, such as a fighter plane, are developed as a result of a long term and costly research and development programme. In order to help arms manufacturers limit their financial risk, the purchasers of arms, usually the government, guarantee a given rate return on costs, often negotiated by reference to the industry average rate of return.
Rate of return pricing is not entirely unknown in the health care industry. In the United Kingdom, the Pharmaceutical Price Regulation Scheme limits the profits of companies by a 'claw-back' of revenues if these exceed an agreed level, although the prices of individual drugs in the UK are increasingly being determined based on value for money criteria.

However, rate of return pricing has its critics. The first concern is that is often difficult to obtain an accurate estimate of the true costs of developing and marketing a given product and there is considerable scope for manufacturers to inflate costs through accounting practices. Secondly, if the manufacturers know in advance that their costs will be covered, they have few incentives to be efficient in the research and development process. This is a particular problem in the defence sector, where the technical challenges to achieve product specification may be great and projects often overrun in both cost and time, pushing up procurement costs. A third challenge is that RoR pricing discourages competitive entry as returns are capped, reducing the incentive for others to enter offering a better product. Fourthly, the rate of return may be set too low (deterring innovation) or too high (encouraging excessive innovation).

\section{Could rate of return pricing be helpful in health care?}

In the first of the situations discussed above, Berdud et al. [1] have proposed a rate of return approach for establishing a reasonable price for an orphan drug. Acknowledging the concerns of Côté and Keating [3], they argued that although society may be willing to sacrifice some health gain overall to make treatments for orphan diseases available, it would not tolerate a situation whereby the manufacturers of these drugs make substantially higher profits than those manufacturers of drugs for non-orphan conditions.

Therefore, they proposed the derivation of an adjusted cost-effectiveness threshold, based on the differences between orphan and non-orphan drugs, both in the relative costs of research and development and the relative size of the anticipated patient population. (Research and development costs are likely to be lower for orphan drugs, as the Phase III trials are typically smaller, but revenues are also likely to be lower because of the small patient population.) They argued that the adjusted threshold determined by the equivalence of rates of return would imply a higher price than the VBP, giving an indication of the maximum price society might pay in order to make these drugs available to patients. They were careful to point out that this did not indicate a price that society should pay, but that it could provide some reassurance to policy makers that, although they were paying more than the VBP, they were not paying 
excessive prices in order to make these drugs available. That is, the rate of return price might serve as a useful benchmark in the price negotiation.

In considering the second case, where a 'cure' becomes available for a disease that currently has high treatment costs, the value-based price might be very high. Here, a price based on rate of return would likely be lower than the value-based price and could be viewed as the minimum price society might be willing to pay. Again, this does not indicate that this is the price society should pay, as a higher price might be justified in terms of rewarding the manufacturer for an important innovation in care. However, the rate of return price might again serve as a useful benchmark in the price negotiation.

\section{Practical challenges in using rate of return pricing}

Using rate of return pricing for pharmaceuticals gives rise to a number of challenges. First, the high failure rates in drug discovery mean that most R\&D does not lead to a product. Therefore, the cost of failures has to be factored in to the calculation of the rate of return price and there are likely to be differences in opinion on how this should be done. Secondly, R\&D in pharmaceuticals is a global activity and manufacturing plants supply many countries. Rules for allocating these global costs between countries are inevitably arbitrary. Thirdly, as mentioned above, rate of return pricing would not give enough incentives for manufacturers to be cost effective in research, nor to pursue the most important (valuable) disease targets, as the allowed return would be the same whatever area is explored. Finally, capping returns reduces the incentive for competitive entry, and setting the rate too low will discourage R\&D investments valued by society.

In the case of ultra orphans, Berdud et al. [1] avoid most of these challenges by proposing an adjustment to a health system's cost-effectiveness threshold for differences in average cost and revenue for drugs in different bands of patient population size, rather than obtaining cost information for individual products. This approach gives an incentive for generating more QALYs, but does not reward an individual company for having higher than average $R \& D$ costs. A 'cure', however, may well be cost-effective at the ICER threshold, so alternative proxy approaches will be required-in this case to adjust the threshold downwards. These could be based on industry averages for $\mathrm{R} \& \mathrm{D}$ costs, success rates, and rates of return on investment, but include a premium return to reflect the priority society gives to getting cures. However, it would be important to avoid setting the RoR price based on product specific costs, since this would encourage a cost-plus approach by the company concerned.

\section{Conclusions}

We conclude that there may be a role for rate of return pricing in situations where the value-based price is considered to be inappropriate. We also show that the rate of return price could be higher or lower than the value-based price, depending on the particular situation. However, in these situations the rate of return price could be considered as a guide for policy makers, who may then wish to negotiate higher or lower prices, depending on whether they consider other factors, such as rewarding innovation, or ensuring equal access to the new health care technology, are important.

If rate of return pricing were to be applied, it would be important to find ways of dealing with the problems of accurately estimating development costs and providing incentives to manufacturers to be as efficient as possible in the $R \& D$ process. We have suggested the development of proxy methods that do not involve obtaining research and product cost information from individual companies, or require attribution of cost to individual markets. Finally, attention would also need to be given to driving the direction of R\&D in health and medicine. If value-based pricing were universally applied, it would not only improve the efficiency of current care, but also drive research towards the discovery of high value treatments in the future. This incentive would be largely absent in a world of rate of return pricing, and it would be important for society to find other ways of incentivising the types of research that it would like to see. This could involve governments funding clinical development directly, taking on the cost of failure, which is unlikely to be a sensible use of health system resources, or setting higher rates of allowable returns for priority areas, which would mimic one of the desirable effects of using value-based pricing.

\section{References}

1. Berdud, M., Drummond, M.F., Towse, A.: Establishing a reasonable price for an orphan drug. In: OHE Research Paper. London, Office of Health Economics (2018)

2. Claxton, K., OFT: VBP: QED? Health Econ. (2007). https://doi. org/10.1002/hec. 1249

3. Côté, A., Keating, B.: What it wrong with orphan drug policies? Value Health 15, 1185-1191 (2012)

4. Danzon, P., Drummond, M.F., Towse, A., Pauly, M.: Objectives, budgets, thresholds, and opportunity costs - a health economics approach: an ISPOR special task force report [4]. Value Health 21, 140-145 (2018)

5. Danzon, P., Towse, A., Mestre-Ferrandiz, J.: Value-based differential pricing: efficient prices for drugs in a global context. Health Econo 24(3), 294-301 (2015)

6. Drummond, M.F., Jönsson, B., Rutten, F.F.H.: The role of economic evaluation in the pricing and reimbursement of medicines. Health Policy 40, 199-215 (1997) 
7. Mazzucato, M.: The People's Prescription: Reimagining Health Innovation to Deliver Public vAlue. IIPP Policy Report, 2018-10. London: Institute for Innovation and Public Purpose, University College London (2018)

8. McCabe, C., Claxton, K., Tsuchiya, A.: Orphan drugs and the NHS: should we value rarity? BMJ 331, 1016-1019 (2005)
Publisher's Note Springer Nature remains neutral with regard to jurisdictional claims in published maps and institutional affiliations. 